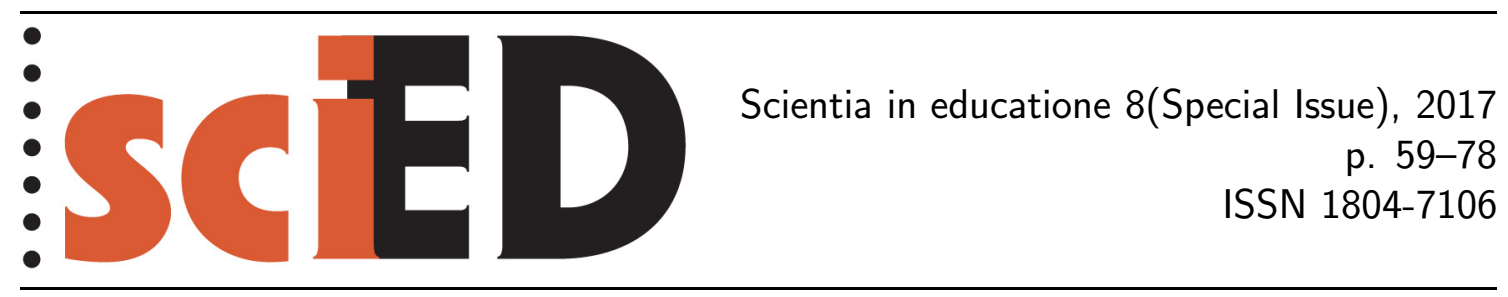

\title{
Physware: A Collaborative Initiative for Strengthening Physics Education and Promoting Active Learning in the Developing World
}

\author{
Pratibha Jolly
}

\begin{abstract}
Project Physware emanates from globally shared concerns on the lack of high-quality education in physics with detrimental consequences on scientific research and socio-economic progress. A significant milestone in international cooperation, Physware aims to provide a sustainable collaborative model for capacity building of physics educators through a series of Educate the Educator workshops for those in the developing countries. The workshops are carefully designed to promote activity based pedagogic methods proven to be effective through rigorous educational research. They propagate curriculum and resource materials that are easily adapted to the needs of any region. While the emphasis is on using lowcost equipment and appropriate technologies that are locally accessible, participants are also introduced to ways of integrating emerging computer-based technologies for physics teaching, contemporary research, and applications of relevance to the work place. They explore ways of teaching fundamental new physics within the context of contemporary pedagogy that is both, hands-on and minds-on. After the success of a pilot workshop held at Trieste in 2009, the Physware series was launched in 2012 from the University of Delhi. Both workshops brought together a vibrant and eclectic group of participants who contributed actively to creation of innovative resource materials. It is hoped that many participants will emerge as regional leaders. Feedback shows that going beyond the constraints of its workshop format, Physware has the potential to emerge as a professionally networked community of practice.
\end{abstract}

Key words: educate the educator, physics education research, active learning, low cost equipment, community of learning and practice. 


\section{INTRODUCTION}

The turn of the century has ushered a greater sensitivity to the common denominator of problems faced by humankind and reinforced the need for finding collaborative solutions. It is widely recognized that in an interconnected world, science and technology will continue to be the key instrument that will decide the pace of further social and economic progress across the globe. The spotlight is now focused on the so-called emerging and developing countries - their potential, changing aspirations and capacity to contribute to global economies. Education and health for all, inclusive growth, greater sensitivity to environmental challenges and issues of sustainability underpin global development agenda and discourse. The national goals of developing countries, in particular, now lay greater stress on access, equity and excellence in education. Recognizing the importance of building a technological backbone employing indigenous research and development programs, the world educational community understands the increasing need to adopt the best pedagogical praxis to meet global benchmarks in the long run (Science, 2013).

Paradoxically, despite the major strides in science, the quality of the human resources in science and technology continues to be an area of grave concern not just in the developing countries but across the world. International surveys and assessment of performance tests such as TIMMS (Trends in International Mathematics and Science Study), ROSE (The Relevance of Science Education) and PISA (Programme for Student Assessment) flag serious issue about the state of science education. Growing apprehensions also include the dwindling interest in science amongst young students, the lack of quality in science education in general, the flight of talent from basic sciences and the evident disconnect between formal education and the needs of the workplace and national goals.

Active Learning: Physware emanates from and builds on the grave concern that, across the world, the predominant mode of teaching continues to be textbook based lectures. Laboratories are sometimes completely missing or not used appropriately as a part of the learning process in both developed and developing countries. Very few institutions, including those in developed countries, provide innovative learning techniques which are integrated throughout the students' learning of physics and which can help students visualize the physics they are learning and enhance their qualitative and quantitative understanding. Even where laboratory work and/or hands-on activities are an integral part of the curriculum, they often follow a cookbook approach that fails to impart procedural and conceptual knowledge about the activity, which then becomes hands-on without engaging the students minds.

Over the last few decades, systematic research in physics education has helped define a new agenda for teaching-learning environments the world over. Seminal research in physics education and cognitive science has conclusively established that students learn best when they are actively engaged in construction of their own knowledge. Active learning strategies entail engaging students in a carefully guided process of scientific enquiry that helps them to construct their knowledge of physics concepts by direct observation of the physical world.

Research on students' conceptual understanding shows that students bring to the formal classroom spontaneous reasoning based on naive theories about the world. These beliefs and ways of interpreting physical phenomena are significantly different from those they are expected to learn. To engender conceptual change, it is necessary to explicitly confront the students with situations that help them perceive 
the inconsistency or contradiction between their naive theories and the evidence generated by the phenomena. The resulting disequilibrium can provide the crucial intrinsic motivation for active learning. Guided enquiry methods make use of a learning cycle that includes predictions, small group discussions, observations and comparison of observed results with predictions. The goal is to make students aware of the differences between the beliefs that they bring into the introductory physics classroom, and the actual physical laws that govern the physical world. These learning strategies are known to measurably improve conceptual understanding and simultaneously aid development of good physical reasoning skills. Consequently, the current thrust is to develop active learning environments, instructional material and teaching strategies which are both, hands-on and minds-on (McDermott, 1999; Laws, 1997).

Rubric for Change: Developing and implementing active learning environments is no easy task. There are many reasons that we still have stagnant and traditional curricula. Active learning requires resource material tuned to the local framework. It needs basic equipment that is easy to procure - available off the shelf and affordable; easy to operate — with appropriate level of sophistication; easy to maintain - with available local technical support; robust — of good educational quality. Some of the equipment should be sufficiently modern - reflecting the state-of-art in education as developing communities also aspire for the best.

There is no clear rubric for change. The overwhelming question for any group attempting educational reform is where to make a beginning. Deep-rooted change affords no shortcuts. It is well recognized that import of curriculum packages, resource materials, experimental kits and equipment, however proficient, cannot fill the lacunae in individual programs. The "not invented here" syndrome can often lead to the collapse of an otherwise excellent idea transported from elsewhere. Thus, it is imperative for each group to continually look into the methodology and content of its programs and develop its own materials and mechanisms taking into account the special constraints in implementation. In education, the wheel has to be continually reinvented. Individual adaptations are necessary and unavoidable - in fact, it is the process of development itself that is of prime importance (Jolly, 2002).

Teacher Education: The role of the instructor when active learning materials are introduced into the classroom is of critical importance. This transition requires teachers to accept evidence that most introductory students do not learn effectively from logical explanations by instructors. Teachers must believe in the effectiveness of active learning materials. The ease of this transition is dependent not only on a willingness to give up the role of authority, but also on a number of cultural factors that differ from country to country. This is the ultimate challenge in introducing active learning teaching strategies in different parts of the developing world, and is a vital reason for designing activities that use low-cost equipment.

Large scale curriculum reform rests on creating several opportunities for professional growth for teachers. Onetime participation in a programme, however well conceived, is merely a positive spike that enhances motivation and professional competence for a short duration. The moot question is how transformative this trigger is and how deep rooted the change it brings about. Once back in the environment of their own country, institution and context, will the participants be able to bring innovation into classroom practice and leverage the enhanced pedagogical content knowledge. Diffusion and assimilation of innovation brings its own challenges. Large scale adoption and adaption of any new idea entails institutional commitment to systemic change, multi-dimensional support and most importantly, 
a critical mass of those who can affect the change, in letter and in spirit. Then the foremost requirement for transforming educational ecosystems is empowering and educating the educator and changing the understanding they have of the process of teaching-learning (Jolly, 2001).

\section{BACKGROUND}

Physware, conceptualized as a series of Educate the Educator workshops, is an initiative launched to enhance the quality of physics education at the undergraduate level, especially in the developing world. It is a direct outcome of recommendations from the physics education task force of the World Conference on Physics and Sustainable Development (WCPSD) from 30 October to 2 November 2005, at Durban, South Africa.

\section{WORLD CONFERENCE ON PHYSICS AND SUSTAINABLE DEVELOPMENT (WCPSD)}

Organized as part of the International Year of Physics (IYP) celebrations, WCPSD was co-sponsored by the Abdus Salam International Centre for Theoretical Physics (ICTP) at Trieste, Italy, the International Union of Pure and Applied Physics (IUPAP), UNESCO and the South African Institute of Physics (SAIP). WCPSD was different as it was visualized as the starting point of a long term world-wide initiative. The organizers identified that if physics is to impact sustainable development, there is need to understand and suggest action plans for the coming years in four critical areas, namely, Physics Education, Physics and Economic Development, Energy and Environment, and Physics and Health. The author Pratibha Jolly as Chair of IUPAP Commission 14 - the International Commission on Physics Education (ICPE) - and Priscilla Laws (Dickinson College, USA) were invited to co-chair the physics education segment. The Secretary of ICPE, Dean Zollman (Kansas State University, USA) joined the efforts as a key member of the Planning Committee that also included Minella Alarcon, Program Officer in charge of Basic Sciences at UNESCO and Associate Member of ICPE.

Physics Education Goals: One of the major concerns of WCPSD was to involve those in developing countries and help strengthen physics education in culturally relevant ways, determined and sustained by local initiatives. The Planning Group identified through its own network potential participants, especially from the developing countries. This stakeholder group joined an electronic forum to exchange views on the specific issues to address, themes for invited talks and breakout discussion for action planning. Vibrant discussions led to identification of guidelines for action planning. It was decided to limit focus to the improvement of physics education at the secondary and the university level, especially for future physics teachers in secondary schools. Further, it was decided to set up working groups at the conference to identify the common denominator of problems and suggest how best to promote basic physics teaching that is enhanced by the use of locally developed examples, assignments and projects that are familiar to teachers and their students.

WCPSD Action Plans: The WCPSD concluded with the formulation of specific action plans: 
1. To give educators and students in developing countries access to high quality physics education resources by establishing a website and Physics Education Resource Centres in Africa, Asia and Latin America.

2. To develop supplemental instructional materials for secondary physics courses that help students understand how the mastery of physics concepts can enable them to contribute to sustainable development in their own countries.

3. To develop model workshops for teacher-trainers in Asia, Latin America and Africa that exemplify how active learning methods can be adapted to help meet the needs of students in developing countries.

4. To establish a structured multi-disciplinary mobile science community that provides support to mobile science practitioners, enabled by a website at http://www.mobilescience.info hosted by the Institute of Physics (UK).

The action plans were endorsed by all sponsors. IUPAP, in particular, reported the action plans at the meeting of its Council Chairs and Executive Council held at Institute of Physics, London in February 2006. The WCPSD Planning Group through ICPE was given the mandate of development of model workshops and resource materials for physics teachers and teacher trainers that exemplify how active learning methods can be adapted to meet the needs of students in developing countries and further, mechanisms for electronic sharing of high quality physics education resources by establishing a website. In view of its ongoing work, Institute of Physics UK, was given charge of implementing the last recommendation on Mobile Science (Jolly, 2006).

\section{IUPAP RESOLUTION ON ACTIVE LEARNING AND HANDS-ON EDUCATION}

In furtherance of its commitment to the WCPSD action plans, IUPAP adopted a resolution on importance of active learning, hands on education and laboratory work at the $26^{\text {th }}$ General Assembly held in Tsukuba, Japan, in October 2008 (IUPAP website). The resolution urges that National Governments, Physical Societies, Funding agencies, Physicists, and Physics educators in all countries

- support best practice of physics education and physics education research at all levels by encouraging teaching methods, including laboratory work, that actively engage the hands and minds of learners.

- make available funds for establishment of well equipped laboratories and designing appropriate curricula that lay particular emphasis on teaching the skills of the experimenter.

- support indigenous development of low-cost instruments, physics apparatus and equipment, and - when finances allow it - computer-based data-acquisition systems for real-time measurements at the appropriate level of sophistication for a variety of uses in teaching of physics in the classroom and the laboratory.

- support curricula that teach physics with an appropriate diversity of methods, including hands-on approaches, that encourage critical thinking and help students understand how physics is relevant to their local cultures and to a sustainable future for humankind.

To help give effect to the resolution, the IUPAP General Assembly also supported the suggestion of ICPE that 
- special sessions be organized on educational aspects of hands-on learning, experimentation, and appropriate assessment, in discipline specific conferences of the IUPAP commissions.

- multinational collaborations and workshops be organized for design and development of resource material for active learning and laboratory work; and further, dissemination through professional training of physics educators.

- electronic resource centres be established for exchange of ideas about local initiatives, teaching materials, prototypes of "hands-on" equipment, in particular those that can be locally adapted for construction by the teachers and their students, to serve a variety of educational needs in diverse cultural contexts.

The adoption of this resolution is a milestone that recognizes the importance of dissemination of best practice in physics education and reiterates the urgent need to give a boost to physics education if research in physics is to thrive.

\section{Promoting ACtive LEARNING: AN EXAMPLE OF PRAXIS}

A concerted effort has been made to implement the WCPSD Action Plans by all the sponsoring organizations and key players. Workshops to promote Active Learning have been on top of the agenda.

UNESCO Workshops on Active Learning in Optics and Photonics (ALOP): Within the framework of the UNESCO program for basic sciences, an international team of resource persons, led by Minella Alarcon has organized numerous workshops on Active Learning in Optics and Photonics (ALOP) in various developing countries such as Tunisia (March 2005); Morocco (Cadi Ayyad University, Marrakech, April 2006); India (Miranda House, University of Delhi, November 2006); Tanzania (Dar Es Salaam University, July 2007); Brazil (Universidade de São Paulo, July 2007); Mexico (Leon Guanajuato, November 2007); Argentina (2008); Mozambique (2008), and many more. The outreach till date is more than 600 teachers.

ALOP is a week-long workshop designed for teacher trainers from developing countries focusing on optics and photonics. This is an exciting area of study enabling research on the frontiers with capstone applications in diverse fields using high end technologies. Starting from introduction to light, geometrical optics, optics of the eye, interference, diffraction and spectroscopy, the workshop coherently introduces advanced topics of atmospheric optics and optics in communication. Participants are challenged with intriguing questions on how information is carried by light waves, how light is recorded as an electrical signal, how optical fibres transmit information and what internet communication is all about. The activity based curriculum includes a well-structured training manual. Each module embeds handson experiments and activities that can be locally fabricated or set up using easily available inexpensive materials. Each module also integrates concept questions and provides the PER-based Light and Optics Concepts Evaluation (LOCE) tool to measure student learning. The end-of-unit topics motivate teachers and their students to learn basic physics in order to understand new areas of science and technology that are highly valued in the global economy. For better dissemination, the ALOP Manual has been translated in other languages such as Spanish, Portugese and French to widen outreach, especially in Latin America and Africa.

The ALOP workshop serves as a paradigm for efforts to promote throughout the world the educational goals set by WCPSD (Laws, 2008). 


\section{THE PHYSWARE INITIATVE}

As a direct follow-up on the WCPSD and IUPAP mandate, WCPSD co-Chairs Pratibha Jolly, Priscilla Laws joined by Dean Zollman and Elena Sassi proposed the idea of organizing a series of Educate the Educator workshops titled Physware.

Mission: The core mission of the Physware initiative is to impact quality of physics education at the secondary and undergraduate level through collaborative workshops carefully designed to promote active learning methods using prototypes of affordable hands-on equipment that can be locally adapted for construction by teachers and their students throughout the developing world. An important facet is simultaneously providing an exposure to appropriate technologies, computer-based tools and open source softwares for enhancing conceptual understanding, in tune with changing aspirations of developing communities. The goal is to integrate handson activities within carefully crafted active learning instructional materials so that these can be used effectively.

The Physware initiative aims to go beyond its workshops by also providing a forum to physics educators to share experiences and exchange ideas about dissemination of active learning methods. It is hoped that they will lead similar efforts in their local regions. In the long term, Physware envisions creating and strengthening regional and international networks of physics educators who can adopt global best praxis anchored in physics education research — giving due credence to locally meaningful adaptations situated in local contexts.

\section{Pilot WORKShop: Physware 2009}

Within this framework, the first Physware was held at ICTP, Trieste, from 16 to 27 February 2009 with above listed four as co-directors and Joseph Niemela from ICTP as local co-ordinator and facilitator. Financial support primarily came from ICTP.

Theme: Teaching of Newtonian Mechanics was chosen as the topic for the first workshop.

Participants: In addition to the ICTP publicity network, a concerted attempt was made by the directors to outreach physics education communities by distributing the workshop poster at several physics education events across the world, posting it on pertinent websites and newsletters such as that of ICPE. A record number of more than 200 applications from 48 countries were received, posing a challenge to selection. A rigorous scrutiny enabled selection of 32 participants from 27 countries spread across Africa, Asia, Latin America and Europe. The participants represented a multicultural but eclectic group of extremely talented and innovative physics teachers, teacher-trainers and administrators - some bearing multiple responsibilities. Preference was given to those with demonstrated expertise in developing handson activities and potential for assuming leadership role in organization of similar workshops.

Technical Sessions: The two week workshop (with 10 working days) was structured to have four blocks of one hour forty five minutes on each day. Additionally, seven days included a two hour post dinner block to accommodate poster sessions and special discussions. At the outset the participants were given an exposure to seminal physics education research in the context of mechanics. Early discussions compared and contrasted traditional teaching methods with strategies underpinning enquiry-based active learning environments. Participants were intro- 
duced to research on students' conceptions of mechanics, research-based concept tests, diagnostic tools and learning cycles that promote active engagement in the context of teaching-learning of kinematics and dynamics. The workshop manual drew on eclectic resources drawn from University of Washington Tutorials, Workshop Physics, Interactive Lecture Demonstrations, Learning with Physics Suite, The AMSTEL resources, Naples PER group material, the Uganda Project and University of Delhi Interactive Lab Tutorials (Redish, 2003; McDermott \& Shaffer, 1998; Sokoloff \& Thornton, 1999, 2004; Laws, 2004; Laws \& Teese, 2009; Jolly \& Bhatia, 2001).

Low-cost Locally Fabricated Set ups: The first week modules embedded activities designed using locally available materials. This mandate led to development of several rough and ready set ups and innovative measurement procedures. For instance, different length pendulums were used as clocks to measure time in arbitrary units. Pendulums were fabricated using walnuts, metal nuts, lengths of vine or thread. These were used variously to investigate oscillatory motion and the effect of changing various physical parameters. A mahogany flower pendulum was used to study damping as petals were gradually peeled off to change its shape, and then put back so that the mass was restored but not the shape. There was much experiential learning with kinesthetic involvement as distance was measured in arbitrary units, innovative clickers were used for equal interval timing to graph motion. The do-it-yourself approach led to fabrication of an interesting range of hand-made carts, dynamic tracks and frictionless surfaces. Battery operated toy fans mounted on carts generated interesting variations in motion. Furniture was juxtaposed to study rolling down makeshift inclined planes. Force was measured with rubber bands and then springs. It was found that acceleration due to gravity could be measured fairly accurately merely by timing the fall of a coin. Later the ubiquitous cell phone provided a convenient mechanism for accurate measurement of time.

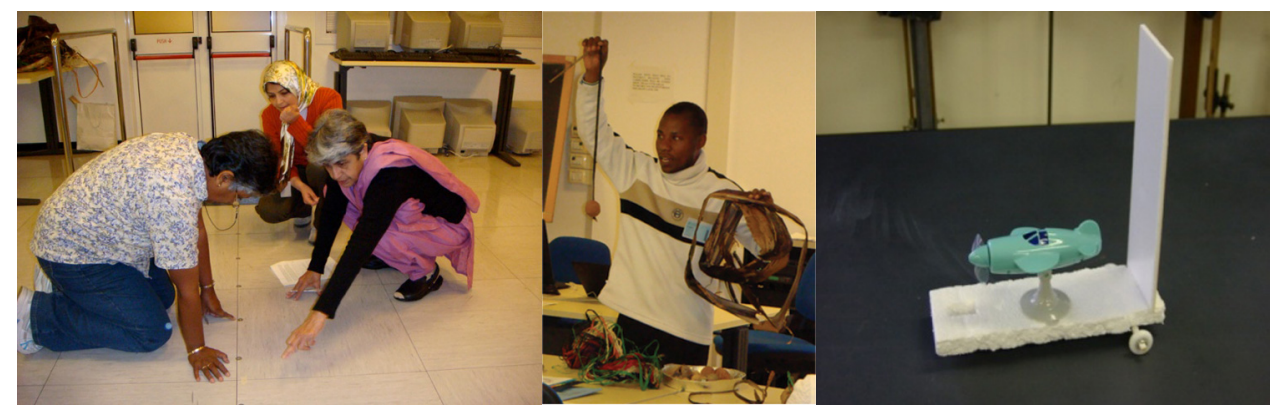

Figure 1: Learning with low cost alternatives

Appropriate Technology-mediated Learning: In the second week, the participants were given a rigorous exposure to appropriate technologies and computerbased measurement. These included use of motion and force sensors, photogates; data and graphical analysis software; and free/open source software. Powerful video data analysis tools were used to analyze video clips of interesting motions such as that of a basketball thrown by a player in action. Participants also created short video clips of objects in motion. A session was devoted to how simulations can be integrated into the learning cycle to enhance conceptual learning. Discussions veered on need to judge if a particular simulation is an appropriate representation of the phenomena or experiment, if it can replace the engagement with the physical world, and how best to judiciously overlay a simulation on a hands-on activity. 
The pedagogic strategy of introducing technological refinement only after having worked without it made the participants compare and contrast the two approaches. On one hand - recalling the great excitement of designing and fabricating one's own minimalistic experimental set up - they were able to realize how much conceptual learning can take place without access to sophisticated instruments. On the other hand, they could appreciate the enabling role of technology in enhancing conceptual learning, visualization, and rigorous in-depth investigations.

Expanding Horizons: Two special sessions were organized to introduce the participants to virtual instrumentation project ongoing at the ICTP M-Lab; and construction of communication networks using low-cost wireless technologies. The contemporary value of demonstrations generated a great deal of interest. In another session, the participants evaluated features of low-cost computers, including the much in news "one hundred dollar" computer from MIT.

Projects: The touchstone of Physware was collaborative work on projects in small groups. This generated a vibrant atmosphere simulating an effective active learning environment that can be replicated for students. Following the structure of the workshop, the projects in the first week entailed creative use of low-cost materials in active learning of topics of core importance in mechanics. The group presented the work through posters. In the second week, projects judiciously used appropriate computer-based technological tools. As many as fourteen projects were carried out in a span of a day. All the groups made power point presentations. As an illustrative example, one of the projects evaluated effectiveness of different technologies to measure the time of free fall. This entailed real time data acquisition using a motion sensor, video capture and a cell phone as a timing device. Subsequently this work was refined and published (Rocha et.al., 2011). It is interesting to note that the collaborating team had members from five different countries, namely, Brazil, Columbia, Venezeuela, Argentina, and Cameroon. Without Physware, such a group would never have found an opportunity to collaborate and publish jointly.

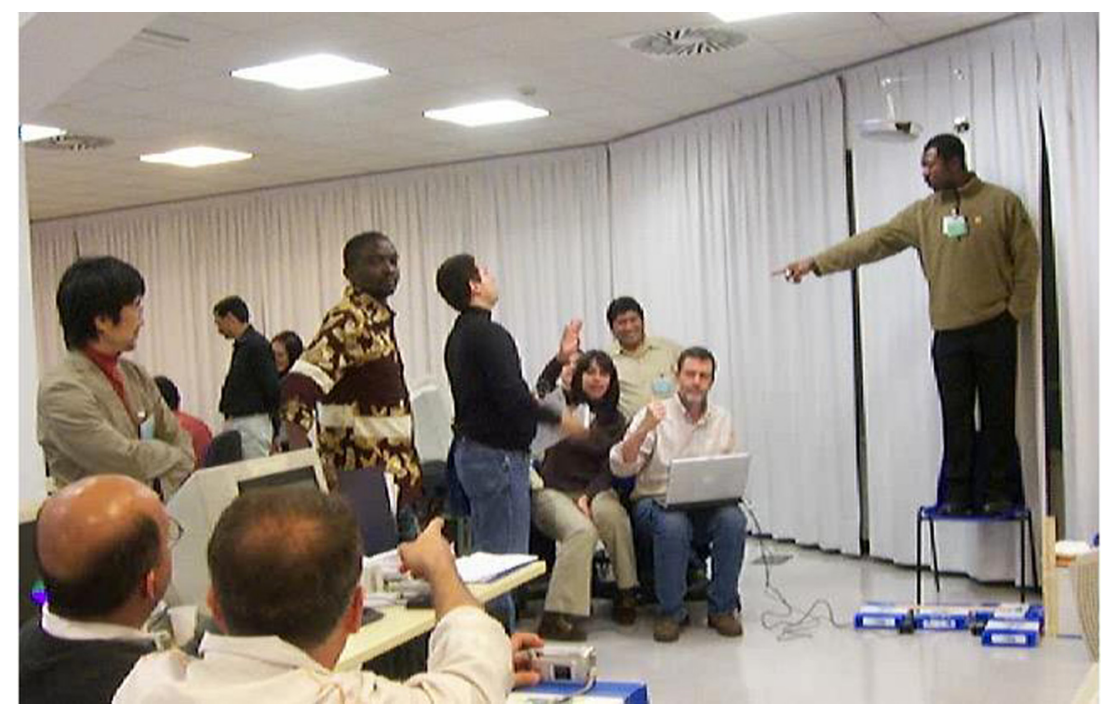

Figure 2: Comparing three different technologies to measure fall of an object

Outcomes: A measure of the success of the pilot workshop was the immense enthusiasm and diligence with which the participants worked until late at night as sessions stretched to $10 \mathrm{pm}$ on most evenings. Feedback of the participants on formal evaluation forms was extremely positive on all counts. 


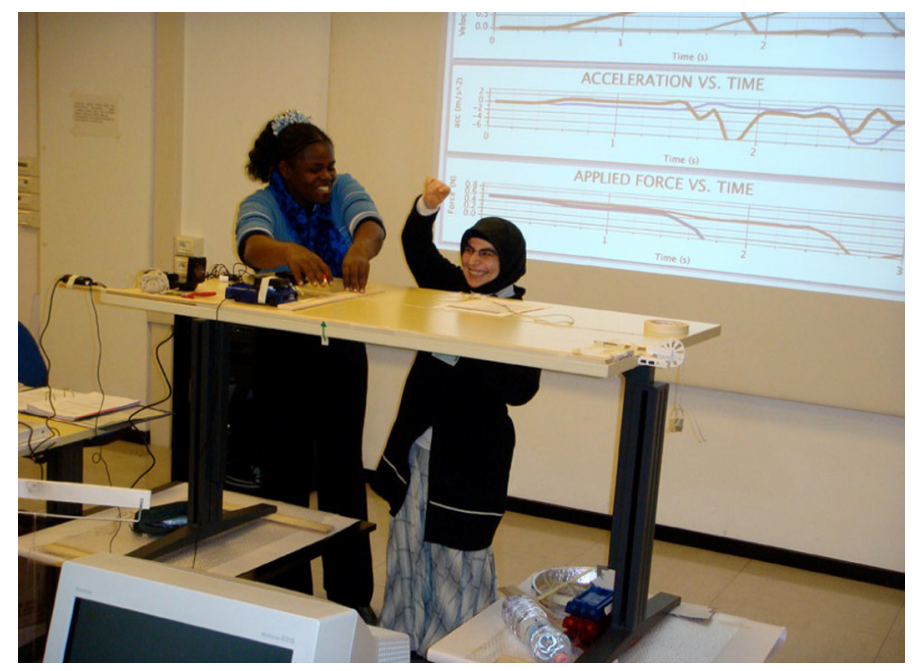

Figure 3: The Aha Moments!

Figure 3 captures the spontaneity of the Aha Moments! This stands testimony to the uninhibited active engagement and joy of learning as the teacher participants assumed the role of students at the workshop.

Sharing Concerns: Early in the workshop, the participants were encouraged to participate in evening poster sessions where they could present illustrative extramural and synergetic activities they were engaged in; innovative projects undertaken; interesting informal learning initiatives; or some aspect of physics education in their home institution or country. This served the dual purpose of breaking the ice and identification of areas of mutual interest and work. The presentations also served to identify the large common denominator of problems faced by all countries.

Evening discussion sessions spanned a wide range of topics. For instance, the issue of under representation of women in physics was discussed. Participants shared informal statistics, country reports, personal experiences and successful initiatives to reverse the trend. The organizers shared the proceedings and resolutions emanating from the three IUPAP sponsored International Conferences on Women in Physics held at Paris 2002, Rio de Janeiro 2005 and Seoul 2008. As a natural extension, issues of multicultural and multiethnic classroom followed.

Towards Advocacy: An important development was that then Director ICTP, $\mathrm{K}$ Sreenivasan, remained proactively tuned in and spent several hours interacting with the participants, formally and informally. He listened carefully to the problems of physics education in developing countries and the need for ICTP to initiate programs in the area. The participants functioned well as an advocacy group and urged ICTP to continue support to Physware and further, facilitate a web-based system for sharing resources. The group also deliberated separately to provide inputs to an action plan for consolidating Physware as a series of global and regional workshops.

Leveraging Social Technologies: The Directors created a Wiki before the workshop for pre-workshop interactions to understand participants' background, needs and to set the agenda. The workshop related information and resource material was made available on the Physware website created by ICTP on their portal (Physware workshop, 2009). However, the highlight of the workshop was the creation of a Physware Discussion Group and a Blog during the workshop by one of the participants. She volunteered to be the webmaster and ably led the participants through a special tutorial on how best to use the blog. Others were quick on uptake and throughout the workshop used the sites for exchange of information, resources 
and discussion on several threads. Social technology became the enabling lifeline for personal bonding, group communication and collaborative professional growth. Participants were quick to realize that the virtual forum would help them overcome geographical divide and personal isolation; it would help them sustain the dialog and the work begun.

Motivating Regional Leaders: As envisioned, the pilot workshop successfully established a primary network of outstanding physics teachers from developing countries with an overview of validated best practices in physics education. These educators expressed enthusiasm about sharing their Physware experience and building on it to find solutions to regional and local physics education problems. Since then, some participants have taken a lead role in organizing active learning workshops in their region. For instance, Julio Benegas from Argentina led the Latin American Regional South Cone Workshop on Active Learning in Mechanics at Córdoba in June 2009 (Benegas, 2009). He has taken a lead role in creating a strong collaborative network in the region and organized several other programmes.

\section{INSTITUTIONALIZING PHYSWARE}

It was felt that the Physware initiative can be sustained and impact physics education only if it is institutionalized. The original sponsors IUPAP - working through its Commission on Physics Education (ICPE) - and ICTP were seen as the appropriate stakeholders to take the lead role.

Indeed, IUPAP and ICTP share common interests in promoting scientific advancement and high-quality science education in physics and its applications. IUPAP is serving to advance the worldwide development of the physical sciences and to contribute to the application of physics toward solving problems of concern to humanity. The mandate of ICTP includes fostering high-level scientific research in developing countries by providing world-class opportunities for both scientists and students at the post-graduate level. ICTP's role has been pivotal in training and capacity building for strengthening scientific enterprise. It has been continuously developing high-level scientific training programmes with sustained attention on the changing needs of developing countries recognizing that good education is critical to scientific and technological development. Then both organizations have a special focus on the needs of the countries where physics is less developed. A fruitful cooperation between the two institutions in furthering the cause of physics education would serve their common interests better.

In October 2009, the President of IUPAP - acting on behalf of ICPE - and the Director of ICTP signed a Memorandum of Understanding (MoU) for a five year action plan. Under this, it was envisaged that ICPE and ICTP would cooperate in organizing the Physware Educate the Educator series of collaborative workshops to promote active teaching-learning in undergraduate physics in the developing world. These would be modelled on the Physware pilot workshop organized at ICTP in February 2009. The goal would be to organize five annual workshops with a developing country and ICTP Trieste alternating as venues. ICPE would be a coordination committee. Each year representatives of ICPE and ICTP, jointly with others as desired, would confer to discuss the funding, venue, organization, experts and resource persons and participants. For the workshops to be held at Trieste, ICTP would make an in-kind contribution and leverage the facilities and expertise in fundamental and emerging physics research available at ICTP, includ- 
ing the facilities and expertise of the Multidisciplinary Laboratory and the Science Dissemination Unit. For the workshops to be held outside Trieste, ICTP would provide institutional contacts for hosting workshops in developing countries and use its resources to provide proper publicity for events. These workshops would focus on innovative physics teaching using contexts of specific relevance to the development of the region in which it is held.

It was clear from the outset that a 5-year effort of this nature could not be undertaken within the existing financial structure of only IUPAP or ICTP. Thus it was mandated that ICTP and ICPE would together solicit funds from both public and private sources with the goal of eventually getting governments and regional professional organizations to take major financial responsibility for the workshops in their own territories. In fact, raising grants has been a far bigger challenge than first anticipated. Despite the commitment to a common cause reflected in the MoU, neither IUPAP nor ICTP was able to allocate an annual budget to the proposals submitted.

\section{PHYSWARE 2012}

Having played the key role in conceptualizing Physware and steering the MoU, the author took up the challenge of raising grants to organize the next workshop in Delhi at her own institution from 26 November to 7 December 2012. The venue was the D S Kothari Centre for Research and Innovation in Science Education (DSKC) established at Miranda House. As committed in the MoU, ICTP sponsored the workshop with partial funding and provided secretarial support from its office in Trieste. The host institution raised funds locally from several government agencies to cover the significant cost of running a two week residential programme.

Theme: The workshop focused on teaching-learning of Electricity and Magnetism in introductory courses.

Participants: The programme was widely advertised using ICTP's official network and also through local efforts. It drew about 200 applications from 44 countries across the world. The directors scrutinized each application with great care to constitute a multicultural group of 46 physics educators from 12 countries, each with an extremely interesting work profile. This group included 25 international participants. Optimising available funds, preference was given to those from neighbouring countries of South Asia, East Asia and Africa, with largest groups coming from Pakistan, Sri Lanka, Philippines and Nigeria. In addition, there were 21 participants from India - drawn from 10 different federal states - representing the vast geographical, socio-cultural and ethnic diversity of pluralistic India. There was no registration fee. All participants were provided full or partial travel support; complete local hospitality and accommodation on campus for two weeks; and workshop material.

Immersion in an Actual Active Learning Environment: Miranda House, college for women at the University of Delhi is amongst the premiere educational institutions in India. It has two extremely well-equipped large undergraduate physics laboratories. In addition, it has two project-based learning studios fashioned after Workshop Physics programme established by Priscilla Laws at Dickinson College, US. The physical layout and design of work tables encourages collaborative work. The labs have networked computers with high bandwidth access to internet and additionally, access to wi fi available across the campus. The college has been leading 
efforts in developing innovative lab curriculum that integrates activities ranging from no-cost, low-cost, locally fabricated set ups to sensor-based real time measurements using computers and handheld devices as data acquisition systems. On one hand, the college is able to pull out bits and pieces of odd materials to put together string and sticky tape experiments with great ease. On the other hand, it has available multiple sets of computer-based systems from Vernier, PASCO, COACH and Labview allowing several groups to work simultaneously on a desired activity. Additionally, the college has a large contingent of laboratory support staff who is well trained to source material locally and find innovative solutions for handson activities. They are always ready to run down to the local hardware shop or the electronic components bazar to procure items not initially anticipated for use. The international directors were delighted to see how quickly ideas translated into activities. All these facets combined to give the Delhi workshop a hands-on mindson edge in contrast to the pilot workshop at Trieste where instruments had to be predecided and ported in limited quantities from elsewhere causing major limitations in scope. More importantly, the location was not a simulation but an actual active learning environment in a college primarily devoted to teaching. The story of how the college incrementally reinvented its environment from traditional to innovative proved to be motivational. Participants saw much that could be easily replicated.

Technical Sessions: Physware 2012 followed the framework of the earlier pilot workshop. However, there were qualitative differences and advantages that accrued from the choice of venue. These made a huge difference to the academic level of the workshop.

Curriculum: Structured course material was put together as a manual. It unfolded a coherent progression of key concepts over two weeks, as summarized in Table 1.

Table 1: Workshop Course Structure and Concepts Covered

\begin{tabular}{ll}
\hline Week 1 & Week 2 \\
\hline Electrostatics & Magnetism \\
\hline Verification of Coulomb's law & Motion of Charges/ Wires in Magnetic \\
& Fields \\
\hline Electric Field Hockey and Rutherford & Magnetic Field around a Current Carrying \\
Scattering & Wire \\
\hline Gauss Law and Faraday's Pail & Motion of Magnets and Coils \\
\hline Representations of Electric Fields & Electromagnetic Induction \\
\hline Representations of Electrostatic Potentials & Faraday's Law, Eddy Currents \\
\hline Basic DC Circuits & Energy Flow in a Simple Circuit \\
\hline Basic Capacitor Circuits & Electromagnetic Waves \\
\hline Active Learning in Advanced Courses & Active Learning in Advanced Courses \\
\hline Projects & Projects \\
\hline
\end{tabular}

Judicious use was made of materials selected from validated physics researchbased curriculums to exemplify active learning of the outlined concepts, foremost amongst them Real Time Physics. Real time measurements and video analysis tools were introduced. An associated reading list drew from seminal work of leading physics education research groups (McDermott \& Shaffer, 1992; Shaffer \& McDermott, 1992; Knight, 2004; Berg, 2012; Meltzer \& Thornton, 2012). Again, the entire material was uploaded on the ICTP Physware website and also on a Google Group created by the Directors for the purpose. 


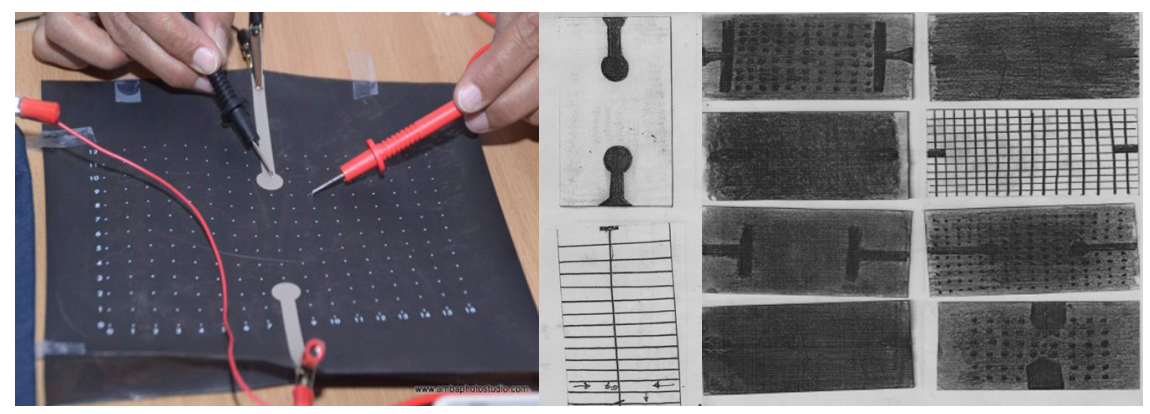

Figure 4: Designs for zero cost carbonized paper with electrodes to plot equipotential "surfaces"

The Jugaad Model of Innovation: The activities leveraged the facilities on hand. A fairly low-cost kit was assembled. In several sessions, a motley collection of wires, magnets and other sundry items were laid on the table and participants asked to demonstrate a principle or concept. They were invariably able to assemble a clever experiment with great dexterity. In India, the art of improvising an ingenious solution with whatever is available is called Jugaad. It is widely prevalent in all spheres of life. In translation, the word would translate as jietinho in Brazil, jua kali in Kenya, zizhu chuanxin in China and systéme $D$ in France. As an aside, it is pertinent to share six principles of Jugaad as identified by authors of a book by that name (Radjou et.al., 2012). These are, to (i) seek opportunity in adversity, (ii) do more with less, (iii) think and act flexibly, (iv) keep it simple, (v) include the margin, and (vi) follow your heart. The last two pertain to the social dimensions of innovation and can help a curriculum developer to extrapolate what would be most appropriate in different settings. In science classes, the Jugaad model allows one to put together the so-called string and sticky tape experiments very innovatively. Of course, Jugaad can often acquire pejorative connotations - it cannot be the sole way of doing things. As and when needed, appropriate level of sophistication and rigour in design must be introduced.

An activity to explore equipotential "surfaces" in two dimensions uses a special conducting paper with electrodes painted on it. Equipotentials are then used to construct field lines. This paper could not be procured in Delhi. One of the lab staff fabricated carbonized paper in a jiffy by rubbing ordinary graphite pencil on a small sheet of paper. Electrodes were also created using the same technique. The participants took instant liking to the idea. Playing around, several innovative ways of shading and growing conducting electrodes were tested. A variety of miniaturized conductive configurations were created using the backside of discarded visiting cards (Figure 4). The exercise generated much excitement amongst participants as discussions began from the concept of a resistance before veering to the task on hand. Other examples abound. A common strategy adopted was to place a few items on the table and ask, what can you do with this stuff? For instance, given a screw, a tiny magnet, a bit of wire, a 1.5 volt battery, it was interesting to trigger imagination and see if a motor could be configured.

Pedagogic Strategies: Participants worked in collaborative groups of 4 to 5 assuming the role of learners with great enthusiasm, negotiating each activity with animated discussions. As stated before, the suggested hands-on activities were designed so that they could easily be replicated in any teaching-learning environment and embedded in any teaching style. The emphasis was on evoking pedagogic strategies which can effectively convert any classroom into an active learning environment. Participants were given exposure to the well-known strategy of using In- 
teractive Lecture Demonstrations (ILD), known to be effective in large classrooms. They were also asked collaboratively to design and present ILDs to communicate a chosen concept. Honouring the immense talent pool, the participants were given freedom to improve suggested set ups, design new activities ab initio and suggest new approaches in all sessions while respecting the time schedule. This resulted in many innovative additions to the repertoire.

Enhancing Conceptual Learning: One of the key objects of Physware 2012 was to introduce the participants to Physics Education Research in the context of the theme of the workshop and the implications for teaching-learning. The directors presented a case study on how the Electric Circuit Conceptual Evaluation (ECCE) was developed based on research. Participants were also introduced to other Physics Education Research-based instructional materials with particular focus on conceptual evaluation on electricity and magnetism. Illustrative examples included those from Real Time Physics and the Brief E\&M Assessment (BEMA) tool, which was used extensively throughout the workshop (Ding et.al., 2006). Select questions from BEMA were embedded in the sessions at appropriate points in almost all sessions, drawing attention to concepts which research shows pose challenge to students learning. All hands-on sessions were followed by in-depth discussions between the entire group and a summative exercise led by the directors.

Expanding Horizons: An invited talk by a young Indian physicist who has been contributing to the ongoing experiments at CERN introduced the participants to particle accelerators and experiments in high energy physics. He spoke on 'Observation of a New Boson at the World's Highest Energy Accelerator' presenting the latest results from CERN on discovery of Higg's Boson. Participants also visited the National Science Centre at Delhi to look at the various interactive models, particularly in the context of the theme of the workshop.

Several sessions were devoted to introducing participants to web based repositories of online resources, open source software, simulations, visualization tools etc. In particular, participants were introduced to the comPADRE and PER User Guide (comPADRE, n.d.). They also explored extensively the PHET Interactive Simulations from the Colorado Project, the MIT Technology Enhanced Active Learning Studio Project (TEAL), the online course on Visualizing Electromagnetic Fields. They discussed how best to integrate the resources in their own teaching. Dean Zollman introduced the participants to his work on Modern Miracle Medical Machines, and particularly medical imaging. A simple analogous simulation using magnetic compasses introduced the complex concept of magnetic resonance imaging. This was followed by an interesting interactive talk on Alexander Graham Bell and Medical Imaging (Kansas State University Physics Education Research Group, 2010). The high level of interest and understanding exhibited by the participants led to fine tuning the depth to which each concept was discussed. Departing from the original plan, the directors introduced sessions devoted to pen and paper tutorials for advanced students. For example, in week one, a tutorial from Oregon State University, "Paradigms in Physics: Designing an Electric Field" was introduced. In Week 2, advanced tutorials were on Faraday's Law and on use of Poynting Vector.

Projects and Presentations: The most exciting feature of the workshop was the collaborative work on projects and the opportunity given to each collaborating group to present their work, incorporating the hands-on demonstration with a powerpoint presentation. Participants displayed immense creativity. Each presentation evoked vibrant discussion. Examples include design of a Gravimeter using magnetic induction for accurate measurement of acceleration due to gravity. 
Challenges: The directors were kept on their toes and required to continuously think out of the box. They needed a high level of competence to meet the challenging questions posed by a well prepared group of physics educators, who were also deeply committed and deeply engaged to the task on hand. Ultimately, no question was too difficult as answers emerged from within the group through Socratic dialogs. All this became possible because of the collaborative spirit underpinning all activities and the knowledge pool available in the collective. This enhanced the confidence of each participant.

\section{CONCLUSIONS AND FUTURE PLANS}

A significant milestone in international cooperation, the Physware workshops described herein provide a sustainable model for capacity building of large number of physics educators, especially in the developing countries. Physware has successfully established a primary network of outstanding physics teachers who have an overview of validated best practices in physics education. These educators are enthusiastic about sharing their knowledge of active learning using low-cost materials and emerging technologies. Given that training and capacity building of physics educators is seen to be the critical first step if young students are to be motivated to pursue careers in physics or contribute to development as envisioned by their national goals, Physware promises to be amongst the most important activities of ICPE in the coming years.

Challenges: Capacity building of educators involves a complex interplay of many factors. Each step in the process of pedagogic innovation, dissemination and diffusion of innovation brings its own unique challenges. The recurring question is how to mainstream innovation. This requires transforming ecosytems. No easy task, this is at best a journey and a work in progress. Very frequently, participation in an innovative programme is a mere spike in the career of the educator. Frequent exposure to best praxis in a variety of new contexts and sustained support during transformative periods is essential. Long term impact can only be assessed on the basis of how well the individual is (i) able to adopt or adapt the new skills and pedagogic knowledge; (ii) able to apply these to improve her own classroom practice in her own home institution despite constraints of existing educational framework; (iii) disseminate the experience gained to create a critical number of like-minded practitioners who can impact the institutional practices in the long term.

The ultimate success of the Physware initiative will depend on growing the circle of influence along three important dimensions, namely,

(i) the range and depth of content - it is important that subsequent Physware workshops should cover more and more topics of physics for comprehensive impact.

(ii) the quality of content - it is important that each Physware workshop should be iteratively refined taking into account the feedback of the participants and further fine tuned to be compatible with local needs and contexts.

(iii) the scale of educational outreach - it is important that a significantly large number of educators in any region should be exposed to the new pedagogies, receive adequate training, and assume the role of regional leader or agent of change to provide opportunities to more and more educators. 
Replicable Workshop Model: The Physware workshop model has salient features that make it amenable for wide scale adoption. It:

(i) uses curriculum and resource material easily adapted to the needs of any region;

(ii) uses low-cost equipment and locally available technologies;

(iii) introduces appropriate technology and applications of relevance to the work place, thereby motivating interest;

(iv) provides ways to integrate topics in contemporary research or applications of these topics thereby introducing participants to teaching fundamental new physics within the context of contemporary pedagogy;

(v) employs activity based pedagogic methods proven to be effective through educational research;

(vi) assesses participant needs and attainment of workshop goals through pre-workshop discussions, on-site feedback and post-workshop evaluations;

(vii) organizes collaborative groups to enhance professional development opportunities for physics educators who teach in developing countries;

(viii) identifies regional leaders who can in turn organize regional versions of Physware workshops thereby reaching out to a critical number of physics educators necessary for affecting change.

Both the Physware workshops described herein have been hugely successful in achieving their objectives. They addressed two different themes and make available well-structured curricular material along with an accompanying activity kits. The same model can easily be extended. It is hoped that each subsequent workshop will address a new topic and create several thematic Physware Manuals with Activity Kits.

Action Plan: The ICTP-IUPAP MoU five year action plan mandated a structured plan for scale up of the Physware initiative and regular organization of the workshops. Figure 5 depicts the vision.

The idea was to develop workshop manual and kits on at least five different topic areas such as Mechanics, Electricity \& Magnetism, Waves and Oscillations, Optics,

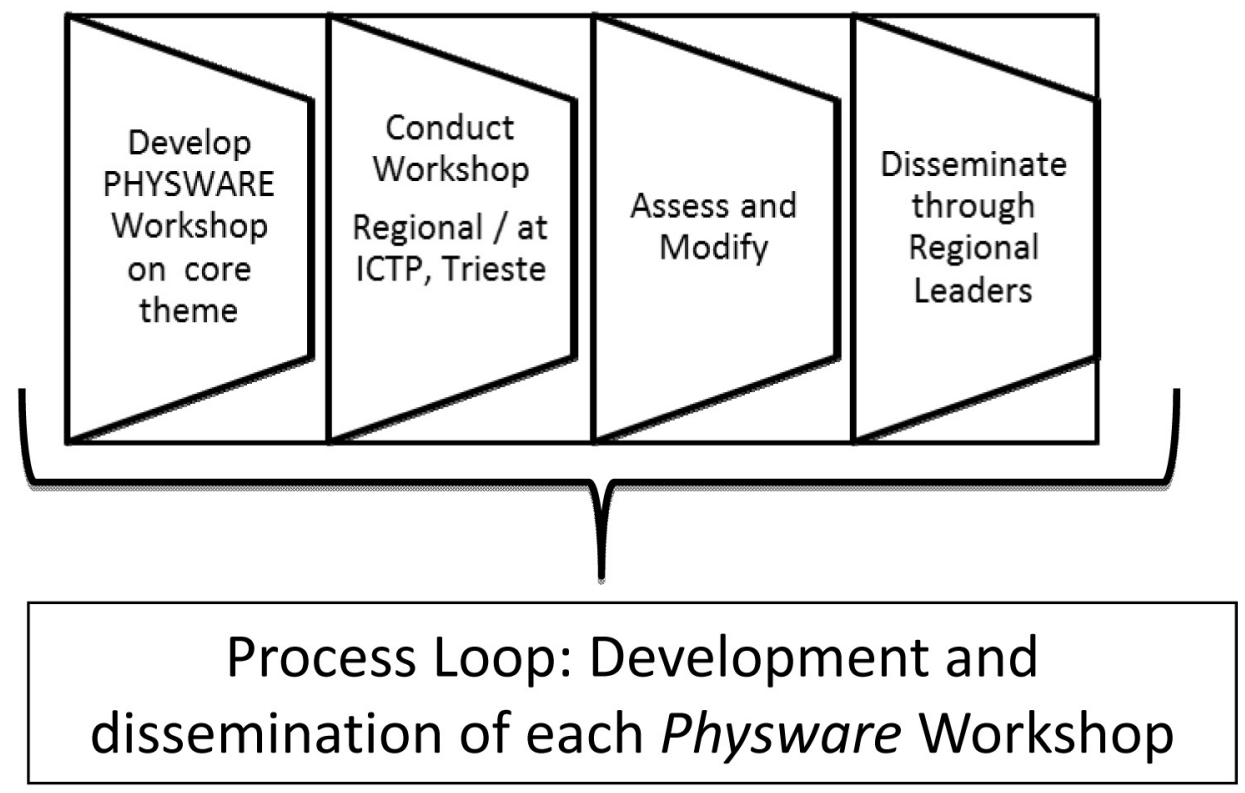

Figure 5: Action Plan for sustained development and outreach through workshops 
and Thermal Physics. A different international team of directors that has broad experience with teaching environments, cultural differences and the educational needs of peoples from many nations would be responsible for each theme. Once executed, the material would be continuously upgraded based on feedback. It would also be made available to participants with demonstrated leadership qualities so that they could conduct similar workshops in their own regions. Further, it was suggested that a special session on Physware should be organized at each ICPE conference to share, evaluate progress and plan future workshops. All this would have a cascading effect and scale up outreach.

Multi-institutional Support: Although Physware is currently the flagship programme of ICPE, ideas have not translated to action as planned. The single reason for this has been lack of adequate dedicated funds. A long term effort of this nature needs multi-institutional support, public and private sponsorship for organization of at least the first set of workshops with the goal of eventually getting governments and regional professional organizations to take major financial and organizational responsibility for additional capacity building workshops in their own territories. Pending such support, it would be prudent to use developing countries as venue with host institutions taking the responsibility of raising funds locally and ICTP providing partial financial support and logistic support.

Building a Physware Community of Practice: Another important clause of ICTP-IUPAP MoU that has so far remained essentially dormant is the commitment to develop a Physware Resource Website for physics educators. It was envisaged that this web based repository of high quality physics education resources would serve the needs of those from countries where examples of best practice are not easily available; consolidate the gains of Physware workshops; and give sustained support to Physware participants for continued sharing of efforts through structured communication. Going beyond, it is crucial to seed formation of a Physware Community of Learning and Practice if participants are to overcome isolation in their home institutes or countries and continue collaborations forged at the workshop while working in their respective countries. The aim would be to undertake sustained computer supported collaborative work to produce concrete outcomes that can be shared globally to impact regional practice of physics education in the long term. No easy task, creating a successful Physware community would require a dedicated facilitating team that is knowledgeable about physics education and teacher education. It remains to be seen if the collaborating organizations led by ICPE can deliver this dream.

\section{ACKNOWLEDGEMENT}

It is a pleasure to thank the Physware co-directors Dean Zollman, Priscilla Laws, Elena Sassi, and ICTP coordinator Joe Niemela for an enjoyable and fruitful collaboration. The Delhi workshop would not have been possible without the support of Miranda House staff, particularly Mallika Verma, the local coordinator of Physware 2012. It is also a pleasure to acknowledge all the Physware workshop participants who are individually responsible for the success of the initiative.

Finally, I dedicate this paper to the memory of Elena Sassi - friend, mentor and co-director who unfortunately is no longer with us. The Delhi Physware workshop was probably her last academic engagement, her last adventure. Vivacious, full of energy, she was always surrounded by Physware participants wanting to learn more from her. She will be deeply missed. 


\section{REFERENCES}

Benegas, J. (2009). Report of the $2^{\text {nd }}$ Regional South Cone Workshop on Active Learning in Mechanics (AAMe-Córdoba'09) and the $2^{\text {nd }}$ Regional South Cone Conference on Active Learning in Physics (CRAAF-2). Available at http://journal.lapen.org.mx/sep09/31_LAJPE_288_Julio_Benegas.pdf

Berg, R. E. (2012). Resource Letter PhD-2: Physics Demonstrations. Am. J. Phys. 80, 181.

comPADRE. (n.d.). Available at http://www.compadre.org

Ding, L., Chabay, R. \& Sherwood, B., et. al. (2006). Evaluating an electricity and magnetism assessment tool: Brief Electricity and Magnetism Assessment. Physical Review Special Topics — Physics Education Research 2, 010105.

IUPAP Website. (n.d.). Available at http://www.iupap.org

Jolly, P. (2002). An Indigenous Process of Pedagogic Innovation: A Case Study on Curriculum Development, AI \& Soc., 16, 148-162.

Jolly, P. (2001). A Refresher Course in Physics Education: Training College Teachers to do Classroom Research. In R. Pinto \& S. Surinach (Eds), Physics Teacher Education Beyond 2000 (249-252). Elsevier.

Jolly, P., Bhatia, V. B. \& Verm, M. (2001). Developing a Research-based Laboratory Curriculum for College Physics (workshop). In R. Pinto and S. Surinach (Eds), Physics Teacher Education Beyond 2000 (319-324). Elsevier.

Jolly, P. \& Laws, P. (2006). World Conference on Physics and Sustainable Development, ICPE Newsletter, 51(3).

Kansas State University Physics Education Research Group (2010). Modern Miracle Medical Machines, http://www.phys.ksu.edu

Knight, R. D. (2004). Five Easy Lessons - Strategies for Successful Physics Teaching. Addison Wesley.

Laws, P. W. (1997). Millikan Lecture 1996: Promoting active learning based on physics education research in introductory physics courses, Am. J. Phys. 65, 14-21.

Laws, P.W. (2004). Workshop Physics Activity Guide: The Physics Suite. Volumes 1 to 4, John Wiley \& Sons, Inc.

Laws, P. W. (2008). A Lens into the World, AAPT Interactions, 21-23.

Laws, P. W., Teese, R. B. \& Willis, C. W., et.al. (2009). Physics with Video Analysis. Vernier Software \& Technology.

McDermott, L. C. \& Redish, E. F. (1999). Resource letter PER-1: Physics Education Research. Am. J. Phys, 67, 755-767.

McDermott, L. C. \& Shaffer, P. S. (1992). Research as a guide for curriculum development: An example from introductory electricity. Part I: Investigation of student understanding. Am. J. Phys. 60 (11), 994-1003.

McDermott, L. C. \& Shaffer, P., et.al. (1998). Tutorials in Introductory Physics. Prentice-Hall Inc.

Meltzer, D. E. \& Thornton, R. K. (2012). Resource Letter ALIP-1: Active-Learning Instruction in Physics. Am. J. Phys. 80, 478. 
Physware workshop (2009). ICTP, Trieste, Italy, Available at http://cdsagenda5.ictp.trieste.it/full_display.php?ida=a07137

Radjou, N., Prabhu, J. \& Ahuja, S. (2012). Jugaad Innovation: A Frugal and Flexible Approach to Innovation for the $21^{\text {st }}$ Century. Random House India.

Redish, E. F. (2003). Teaching Physics with the Physics Suite. John Wiley \& Sons, Inc.

Rocha, F. S. D. \& Fajardo, F., et.al. (2011). Using "Student Technology" in Introductory Physics: A Comparison of Three High Tech Tools to Study Falling Objects. The Physics Teacher, 49, 165-167.

Science (2013). Grand Challenges in Science Education. Special Issue, 340 (6130).

Sokoloff, D. R., Thornton, R. K. \& Laws, P. (1999, 2004). RealTime Physics: Active Learning Laboratories: The Physics Suite. Volumes 1 to 4, John Wiley \& Sons, Inc.

Sokoloff, D. R. \& Thornton, R. K. (2004). Interactive Lecture Demonstrations - Active Learning in Introductory Physics. John Wiley \& Sons, Inc.

Shaffer, P.S. \& McDermott, L. C. (1992). Research as a guide for curriculum development: An example from introductory electricity. Part II: Design of Instructional Strategies. Am. J. Phys. 60 (11), 1003-1013.

PRATIBHA JOLLY

Miranda House, University of Delhi, India 